\title{
A Carrier-Free Folate Receptor-Targeted Ursolic Acid/Methotrexate Nanodelivery System for Synergetic Anticancer Therapy
}

This article was published in the following Dove Press journal: International Journal of Nanomedicine

\author{
Jin-Shuai Lan ${ }^{1,2, *}$ \\ Yan-Hong Qin ${ }^{2, *}$ \\ $\mathrm{Li} \mathrm{Liu}{ }^{2}$ \\ Rui-Feng Zeng ${ }^{2}$ \\ Yang Yang ${ }^{3}$ \\ Kai Wang ${ }^{3}$ \\ Yue Ding ${ }^{1,2}$ \\ Tong Zhang $\mathbb{D}^{1,2}$ \\ Rodney JY Ho ${ }^{4}$
}

'Experiment Center of Teaching and Learning, Shanghai University of Traditional Chinese Medicine, Shanghai, 201203, People's Republic of China; ${ }^{2}$ School of Pharmacy, Shanghai University of Traditional Chinese Medicine, Shanghai, 201203, People's Republic of China; ${ }^{3}$ Science and Technology Experimental Center, Shanghai University of Traditional Chinese Medicine, Shanghai, 201203, People's Republic of China; ${ }^{4}$ Department of Pharmaceutics, University of Washington, Seattle, WA, 98195, USA

*These authors contributed equally to this work
Purpose: To avoid undefined metabolic mechanisms and to eliminate potential side effects of traditional nanocarriers, new green carriers are urgently needed in cancer treatment. Carrier-free nanoparticles (NPs) based on ursolic acid (UA) have attracted significant attention, but the UA NPs targeting the folate receptor have never been explored. We designed a novel self-assembled UA-Methotrexate (MTX) NPs targeting the folate-receptor and its synergetic anticancer activity was studied in vitro and in vivo.

Methods: UA-MTX NPs were prepared using the solvent precipitation method. Characterization of the UA-MTX NPs preparation was performed using a size analyzer, transmission electron microscopy, and UV-vis spectrophotometry. The in vitro $\mathrm{pH}$-responsive drug release capability of UA-MTX NPs was tested at different $\mathrm{pH}$ values. The UA-MTX NPs targeting of folates was determined by comparing the endocytosis rates of cell lines with low or overexpression of the folate receptor (A549 and MCF-7 cells). The cytotoxicity and cell apoptosis of UA-MTX NPs were also studied to determine the in vitro synergistic effects. Combination chemotherapy of UA-MTX NPs in vivo was evaluated using MCF-7 xenografted tumor models.

Results: Compared with free UA or MTX, the water solubility of UA-MTX NPs improved significantly. Drug-release from the UA-MTX NPs was faster at $\mathrm{pH} 5.0$ than $\mathrm{pH} 7.4$, suggesting MTX-UA NPs could rapidly release MTX in the acidic conditions of the tumor microenvironment. Confocal laser scanning microscopy revealed the excellent folate receptor targeting of UA-MTX NPs in MCF-7 cells. Cytotoxicity and cell apoptosis results demonstrated greater antiproliferative capacity of UA-MTX NPs than that of free drug in folate receptor overexpressing MCF-7 cells. Anticancer effects in vivo suggested MTX-UA NPs exhibited good biological safety and could enhance antitumor efficacy due to the combination therapy.

Conclusion: Our findings indicate that the UA-MTX NPs targeting folate-receptors is an efficient strategy for combination chemotherapy.

Keywords: ursolic acid, methotrexate, anticancer, carrier free, targeted drug delivery

\section{Introduction}

Correspondence: Tong Zhang; Yue Din Experiment Centre of Teaching and Learning, Shanghai University of

Traditional Chinese Medicine, I 200 Cailun Road, Pudong New District, Shanghai,

201203, People's Republic of China

$\mathrm{Tel}+862151322318$

Tel +862I 51322325

Email zhangtongshutcm@hotmail.com; dingyue1640@shutcm.edu.cn
Cancer as the primary cause of death has surpassed deaths due to ischemic heart disease worldwide from 2010. ${ }^{1}$ Chemotherapy is the most used approach to treat malignant cancers. However, non-specific delivery of chemotherapeutic drugs could result in serious side effects due to their insufficient accumulation in tumor tissues. ${ }^{2}$ Methotrexate (MTX) is one of the earliest wide-spectrum chemotherapeutic agents identified, and is widely used for treatment of most tumors especially 
leukemia. ${ }^{3}$ It has been reported that MTX could competitively inhibit Dihydrofolate reductase and thereby block tetrahydrofolate synthesis, which could impede the formation of thymidylates and proteins. ${ }^{4,5}$ Moreover, due to its similar structure to folate, MTX is effectively internalized by the cell via specific interactions with folate receptors on cell membranes present in carcinoma and brain tumors. ${ }^{6}$ Thus, MTX not only inhibits the proliferation of cancer cells, but it also exhibits specific tumor-targeting via the folate receptor. ${ }^{7}$ However, on account of the distribution and metabolism of MTX throughout the body, some patients may experience side-effects such as headache, nausea and hair loss, limiting its clinical application. ${ }^{8,9}$ To address the above problems and enhance therapeutic effects, many nanocarriers have been designed for targeted delivery of MTX into tumors. For instance, poloxamer conjugates have been reported to be stable and safe nanocarriers for tumor-targeted delivery of MTX. ${ }^{10}$ However, the majority of nanocarriers have been prepared using inert materials, which may bring about unclear effects on their biometabolism and potential toxicity to normal organs. ${ }^{11}$ Hence, developing a novel drug delivery system that does not involve formulation with inert materials is necessary.

Self-assembly drug delivery systems based on small molecules have been well described in recent years and have specific advantages, such as high drug loading capacity and few side effects. ${ }^{12,13}$ In particular, drugs may play a dual role as both the anti-cancer agent and nano-sized carrier. ${ }^{14}$ Among small molecules with self-assembly ability, such as pentacyclic triterpenes might form nanoparticles (NPs) without the help of carriers because of its nanoscale rigid backbone, amphiphilic nature, and the presence of multiple hydroxyl or carboxyl groups. ${ }^{15}$ Ursolic acid (UA) (3ß-hydroxy-urs-12-en-28-oic acid), a typical pentacyclic triterpenoid, could exhibit excellent nano-scale characteristics by self-assembly. ${ }^{16}$ At the same time, UA shows extensive biological activities and pharmaceutical properties, and its anticancer activities have attracted greater attention. ${ }^{17,18}$ In particular, new nanodrugs can be safely developed by self-assembly. ${ }^{19} \mathrm{Li}$ et al found that the conjugation between UA and the classic drug aspirin could enhance their anti-tumor activity via self-assembly. ${ }^{20}$ Guo et al designed a carrier-free nanodrug delivery system using hydrophobic UA and paclitaxel, which exhibited favorable water stability. ${ }^{21}$ Nonetheless, a folate receptor-targeted delivery system based on UA has never been explored for cancer therapy.
Herein, a self-assembly nanodrug (MTX-UA NPs) based on chemotherapeutic agents MTX and UA was developed to obtain synergistic anti-cancer effects and to reduce side effects. In the MTX-UA NPs, MTX acts as the anti-cancer agent and enhanced tumor-targeting, while UA was used as the nanoscale carrier with anti-cancer ability. The preparation and possible application of MTX-UA NPs for targeted-therapy are shown in Figure 1. The carrierfree MTX-UA NPs have a spherical morphology with a uniform size, and markedly improved the water solubility of UA and MTX. Furthermore, MTX-UA NPs exhibit suitable stability and are characterized by $\mathrm{pH}$-triggered drug release. By targeting the folate receptor, MTX-UA NPs exhibited efficient accumulation at the tumor site, and the synergistic effects between UA and MTX in MTX-UA NPs also enhanced the chemotherapy in vitro and in vivo.

\section{Materials and Methods}

\section{Materials}

UA ( $>98 \%$ pure) was purchased from Adamas Reagent Co., Ltd. (Shanghai, China). MTX ( $>95 \%$ pure) was purchased from Shanghai Bide Pharmaceutical Technology Co., Ltd. (Shanghai, China). Human lung carcinoma cells A549 were provided by the Cell Bank of Type Culture Collection of Chinese Academy of Sciences (Shanghai, China). The human breast cancer cell line MCF-7 were provided by the American Type Culture Collection (ATCC). Fluorescein isothiocyanate (FITC) was purchased from BioLegend, Inc. (San Diego, CA, USA). The 4.6-diamidino-2-phenylindole (DAPI) was purchased from Beyotime Institute of Biotechnology (Shanghai, China). Fetal bovine serum (FBS) was purchased from Biological Industries (Beit Haemek, Israel). Dulbecco's Modified Eagle's Medium (DMEM) was purchased from Hyclone Laboratories, Inc. (Logan, UT, USA). The characterization of nanoparticles was performed, respectively, using the Malvern Zetasizer Nano ZS device (Malvern Instruments, UK), Transmission Electron Microscope (TEM) (FEI, USA), UV-vis spectrophotometer (Agilent, MA, USA), and fluorescence spectrometer (F-7000, Hitachi, Japan).

\section{Preparation of Nanoparticles}

The nanodrug delivery system was prepared in a simple and green approach for self-assembly. According to the solvent exchange method, the solvent type, volume ratio, and drug concentration were investigated to obtain the 


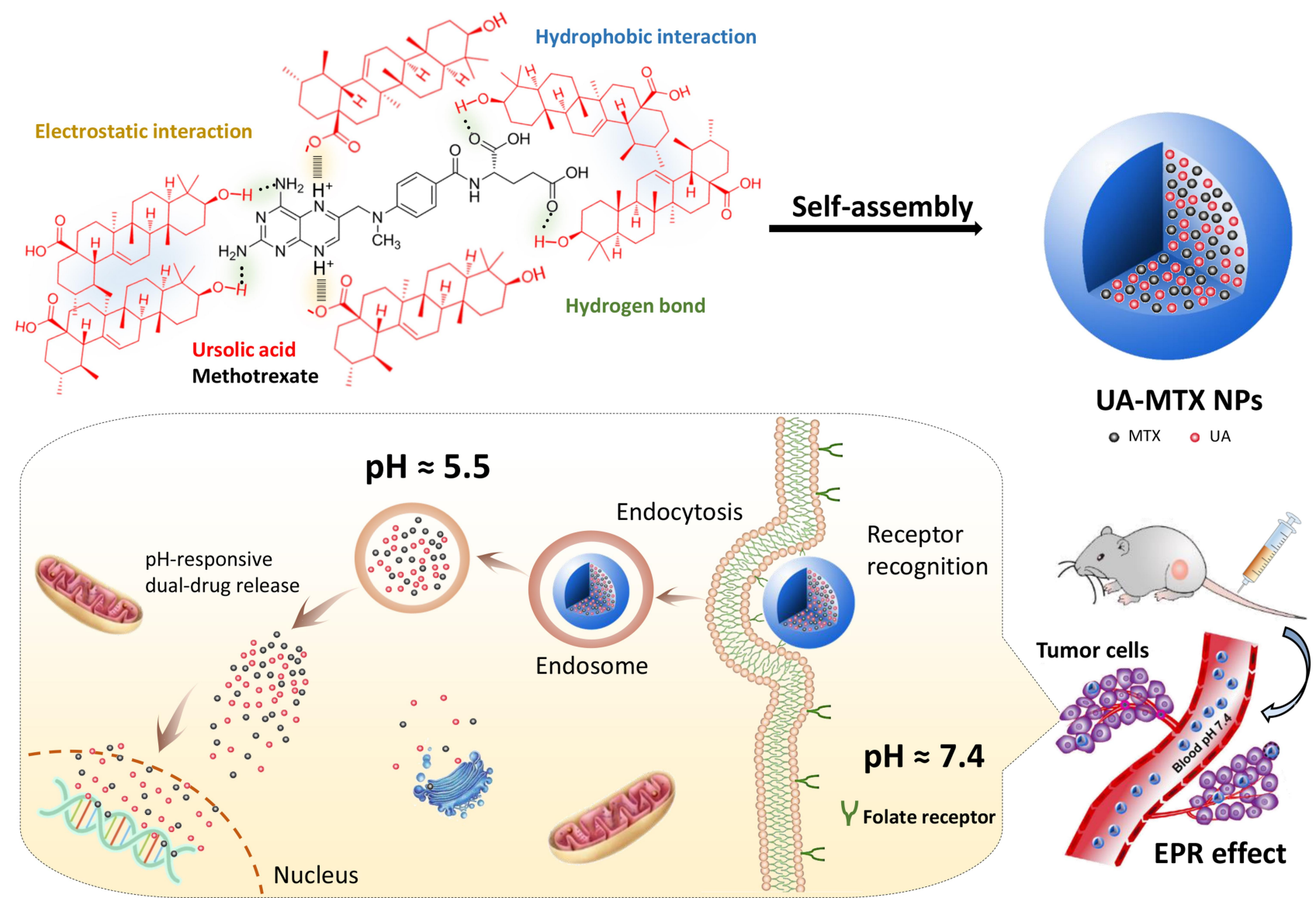

Figure I Schematic representation of the carrier-free nanoparticles (NPs) via co-assembly between UA and MTX.

optimum preparation process. For the preparation of UA NPs, UA was first dissolved in methanol to a final concentration of $5 \mathrm{mM}$. A volume of $400 \mu \mathrm{L}$ UA methanol solution was then dropped slowly into $2 \mathrm{~mL}$ deionized water under vigorous stirring for $5 \mathrm{~min}$ at ambient temperature. Next, then the methanol was evaporated from the mixture under nitrogen. The solution was centrifuged (3000 $\mathrm{rpm}$ for $10 \mathrm{~min}$ ) to remove any precipitate. For further preparation of MTX-UA NPs, MTX was first dissolved in $\mathrm{NaOH}$ solution ( $\mathrm{pH} 12)$ at a final concentration of $1 \mathrm{mM}$. A volume of $0.5 \mathrm{~mL}$ MTX solution was gradually dropped into $1.5 \mathrm{~mL}$ deionized water and then UA was dissolved in methanol $(5 \mathrm{mM})$ was subsequently added into the mixture under vigorous stirring for $5 \mathrm{~min}$. The following steps were the same for the preparation of UA NPs. To perform confocal microscopy imaging, nanoparticles labeled with rhodamine 6G (UA-R6G NPs and MTX-UA-R6G NPs) were prepared using the same approach, with the only difference being that $50 \mu \mathrm{L}$ R6G methanol solution $(0.5 \mathrm{mM})$ was slowly added to the deionized water at the start of the NP preparation.

\section{Characterization}

The size $(\mathrm{nm})$ and zeta potential $(\mathrm{mV})$ of NPs were obtained via dynamic light scattering (DLS) using a Malvern Zetasizer Nano ZS device (Malvern Instruments). The morphology of the MTX-UA NPs was observed by TEM, after the sample was lightly applied to the carbon-coated copper grids and vacuum dried. Meanwhile, the absorption spectra of MTX, UA and MTX-UA NPs were obtained using the UV-vis spectroscopy. The mechanism of nanoparticles formation was also studied by sodium dodecyl sulfate (SDS) and sodium chloride $(\mathrm{NaCl})$ using UV-vis spectroscopy. The photoluminescence of free R6G, UA-R6G NPs and MTX-UAR6G NPs was measured in water using a fluorescence spectrophotometer (F-7000, Hitachi, Japan) in a $1.0 \mathrm{~cm}$ quartz cuvette. To test stability in water, PBS, and DMEM medium (10\% FBS), the size and zeta potential of NPs were continuously measured by DLS at various timepoints. The stability of NPs in solutions at various $\mathrm{pH}$ was also investigated. The drug encapsulation efficiency (EE) and loading efficiency (LE) of MTX and UA in 
MTX-UA NPs was determined by HPLC: the nanoparticles were diluted in methanol (for the UA test) or in aqueous solution ( $\mathrm{pH}$ 12) (for the MTX test) with ultrasound for $30 \mathrm{~min}$ to destroy the nanostructure and released the drug. The formula used to EE and LE were as follows:

$$
\begin{aligned}
& E E(\%)=\frac{\text { weight of drug in nanoparticles }}{\text { total drug used }} \times 100 \% \\
& L E(\%)=\frac{\text { weight of drug in nanoparticles }}{\text { total weight of nanoparticles }} \times 100 \%
\end{aligned}
$$

\section{Drug Release Test}

The dialysis membrane method was used to evaluate drug release. Briefly, $2 \mathrm{~mL}$ free MTX, free UA, and MTX-UA NPs were sealed securely in dialysis bags (Sigma, 5000 MW cutoff) and immersed in $50 \mathrm{~mL}$ phosphate buffer (pH 7.4 and 5.5) containing 20\% (v/v) MeOH. The solutions were then placed in the gas bath thermostatic oscillator at $37^{\circ} \mathrm{C}$ and stirring was maintained at $100 \mathrm{rpm}$. At different time intervals $(0,1,2,4,8,12,24$, and $36 \mathrm{~h})$ the contents of MTX and UA in the samples were quantitatively analyzed by HPLC. To analyze MTX release, the mobile phase was set at A:B $(15: 85, \mathrm{v} / \mathrm{v})$ at a flow rate of $1 \mathrm{~mL} /$ min, where solution $\mathrm{A}$ was $\mathrm{MeOH}$ and $\mathrm{B}$ was $\mathrm{KH}_{2} \mathrm{PO}_{4}$ dissolved in $0.1 \mathrm{~mol} / \mathrm{L} \mathrm{KOH}$ solution to $7 \mathrm{~mol} / \mathrm{mL}$. The temperature of column was maintained at $25^{\circ} \mathrm{C}$. The injection volume was $10 \mu \mathrm{L}$ and the absorbance changes were monitored at $254 \mathrm{~nm}$. To analyze UA, the mobile phase used was $\mathrm{MeOH}$ and $0.2 \%$ phosphoric acid in water $(85: 15, \mathrm{v} / \mathrm{v})$ with a flow rate of $0.8 \mathrm{~mL} / \mathrm{min}$, and the temperature of column was maintained at $25^{\circ} \mathrm{C}$. The absorbance changes were monitored at $210 \mathrm{~nm}$ and the injection volume was $20 \mu \mathrm{L}$. The content of each sample was measured three times and averaged.

\section{In vivo Pharmacokinetic Studies}

Female Wistar rats (weight 250-300 g) were obtained from the Vital River Laboratory Animal Technology Co., Ltd. (Beijing, China) and utilized in all experiments. Female Wistar rats were maintained under a 12/12-h lightdark cycle and had free access to food and water prior to experimentation. Experiments were conducted in accordance with the Guidelines for the Care and Use of Laboratory Animals and were approved by the Institutional Animal Care and Use Committee of Shanghai University of Traditional Chinese Medicine (PZSHUTCM201225009). Before experimentation, 5
Wistar rats fasted for $12 \mathrm{~h}$ and were provided water ad libitum. MTX-UA NPs (MTX $=5 \mathrm{mg} / \mathrm{kg}, \mathrm{UA}=20 \mathrm{mg} / \mathrm{kg}$ ) were intravenously injected into rats. Approximately $0.3 \mathrm{~mL}$ of blood samples were obtained through the postorbital venous plexus veins at predetermined time points after administration $(2,5,10,15,30,60,120,240,360$, $480,720,1440,2880$, and $4320 \mathrm{~min}$ ). The blood samples were centrifuged at $4000 \mathrm{rpm}$ for $10 \mathrm{~min}$ to obtain plasma, which was kept at $-20^{\circ} \mathrm{C}$. A $100-\mu \mathrm{L}$ volume plasma sample was deproteinized with $500 \mu \mathrm{L}$ methanol/acetonitrile (1:1), vortexed for $5 \mathrm{~min}$, and centrifuged at $18,000 \mathrm{rpm}$ for $10 \mathrm{~min}$. Subsequently, the supernatant was chromatographed by UPLC-MS/MS (Agilent 6460 Series, Agilent Technologies, Santa Clara, CA, United States). The mass spectrometry conditions were as follows: capillary voltage, $3500 \mathrm{~V}$; gas flow, $3 \mathrm{~L} / \mathrm{min}$; nebulizer, $15 \mathrm{psi}$; gas temperature, $300^{\circ} \mathrm{C}$; and delta $\mathrm{EMV}(-)$, 400. A $5 \mu \mathrm{L}$ extraction sample was injected into the column (Agilent SB-C18 column, $2.1 \mathrm{~mm} \times 50 \mathrm{~mm}, 1.8 \mu \mathrm{m}$ ) and eluted at $0.4 \mathrm{~mL} / \mathrm{min}$ with a gradient elution of water (with $0.05 \%$ $\mathrm{v} / \mathrm{v}$ formic acid) (A) and $\mathrm{MeOH}(\mathrm{B})(0-1 \mathrm{~min}, 5 \% \mathrm{~B} ; 1-5$ $\min , 5-90 \% \mathrm{~B}$; 5-7 $\mathrm{min}, 90 \% \mathrm{~B}$, followed by reequilibration for $3 \mathrm{~min}$ ). The multiple reaction monitoring (MRM) was performed at $\mathrm{m} / \mathrm{z} 455.2 \rightarrow 455.2$ for UA, $\mathrm{m} / \mathrm{z}$ $469.2 \rightarrow 469.2$ for enoxolone (internal standard, IS) in the negative ion mode, and $\mathrm{m} / \mathrm{z} 455.2 \rightarrow 308.1$ for MTX, m/z $441.1 \rightarrow 294.1$ for aminopterin (internal standard, IS) in the positive ion mode with an electrospray ionization (ESI) source. Pharmacokinetic data were analyzed with DAS (Version 2.0; Mathematical Pharmacology Professional Committee of China, Shanghai, China).

\section{Cell Culture}

Both A549 and MCF-7 cell lines were cultured in DMEM with high glucose, supplemented with $10 \%$ FBS and $1 \%$ streptomycin-penicillin and were maintained at $37^{\circ} \mathrm{C}$ in a humidified incubator with $5 \% \mathrm{CO}_{2}$. The culture medium was changed every two days.

\section{Cellular Uptake in vitro}

To demonstrate tumor targeting, the NPs labeled with rhodamine 6G (UA-R6G NPs and MTX-UA-R6G NPs) were prepared. We studied the cellular uptake of NPs at various time points through confocal laser scanning microscopy (TCS SP8, Leica, Germany). MCF-7 cells and A549 cells were seeded at a density of $1 \times 10^{5}$ living cells per well in single-wells plates holding glass slides and incubated overnight to allow cell attachment. At 1, 2, 3, and 4 
$\mathrm{h}$ before the fluorescence detection, cells were treated with medium containing UA-R6G NPs and MTX-UA-R6G NPs with the same concentration of R6G $(0.5 \mu \mathrm{mol} / \mathrm{L})$. The cells were then washed with cold PBS 3 times, fixed in 4\% paraformaldehyde for $20 \mathrm{~min}$, and then treated with DAPI for $15 \mathrm{~min}$. The cells were evaluated by confocal microscopy. Analyses were performed using LAs AF Lite, version 2.6.0.

\section{In vitro Cytotoxicity Assay}

A standard cell counting kit-8 (CCK-8) assay was conducted to test the cytotoxicity of nanoparticles. Two cell lines with different folate receptor expression levels (A549 cells: almost no expression, MCF-7 cells: overexpression of folate receptors) were seeded in 96-well plates and cultured for $24 \mathrm{~h}\left(1 \times 10^{5}\right.$ cells $\left./ \mathrm{mL}, 0.1 \mathrm{~mL}\right)$. After removing the old culture medium, fresh medium containing UA, UA NPs, MTX/UA and MTX-UA NPs at different concentrations $(5,10,15,25$, and $37.5 \mu \mathrm{M}$ of MTX and 20 , $40,60,100$, and $150 \mu \mathrm{M}$ of UA) were incubated with A549 cells and MCF-7 cells for an additional $24 \mathrm{~h}$. Next, the cells were washed mildly using PBS 3 times, and each well continued to incubate with the addition of $100 \mu \mathrm{L}$ CCK-8 working solution (10\% CCK- $8+90 \%$ DMEM) at $37^{\circ} \mathrm{C}$ for $1 \mathrm{~h}$. A microplate reader (Infinite 200 Pro, Tecan, Austria) was used to detect absorbance value of media at $450 \mathrm{~nm}$. Untreated cells were used as blank controls and all experiments were conducted in triplicate.

CCK-8 assay was also used to confirm the combined effect of MTX and UA at different proportions (1:1, 1:2, 1:4 and 1:8). The combination index (CI) analysis was calculated based on the following formula: $\mathrm{CI}=[\mathrm{CA}, \mathrm{x} /$ $\mathrm{ICx}, \mathrm{A}]+[\mathrm{CB}, \mathrm{x} / \mathrm{ICx}, \mathrm{B}]$, where $\mathrm{CA}, \mathrm{x}$ and $\mathrm{CB}, \mathrm{x}$, respectively, were the concentrations of agent $\mathrm{A}$ and agent $\mathrm{B}$ when achieving $\mathrm{x} \%$ drug effect in a combination treatment. ICx, A and ICx, B defined the single agent concentrations necessary to achieve $\mathrm{x} \%$ drug effect. Synergism occurred when CI was inferior than 1 .

\section{Cell Apoptosis}

Cell apoptosis was evaluated using flow cytometry (BD Bioscience, FACS Aria III). MCF-7 cells were seeded on 6-well plates $\left(1 \times 10^{5}\right.$ cells per well $)$ and incubated with culture medium contained free MTX, free UA, MTX/UA mixture and MTX-UA NPs with the same concentration of MTX $(5 \mu \mathrm{mol} / \mathrm{L})$ and UA $(20 \mu \mathrm{mol} / \mathrm{L})$. Untreated cells served as the control group. After $24 \mathrm{~h}, \mathrm{MCF}-7$ cells were trypsinized and collected by centrifugation to carefully protect the cell membrane from mechanical damage and were washed twice with cold PBS. According to the manufacturer's instructions, a staining solution containing propidium iodide (PI) and Annexin V-FITC diluted in PBS was added to the cells and incubated in the dark for 15 min. Finally, MCF-7 cell populations at early and late apoptotic stages were measured by flow cytometry.

\section{Anti-Tumor Efficiency and Histological Analysis in vivo}

BALB/c nude mice (4-5 weeks old, and weighing $20 \mathrm{~g}$ ) were purchased from the Shanghai Laboratory Animal Center (Shanghai, China). All animals were handled in accordance with protocol procedures, approved by the Institutional Animal Care and Use Committee of Shanghai University of Traditional Chinese Medicine (PZSHUTCM190322012). MCF-7 cells were collected and resuspended in PBS to a final density of $1 \times 10^{7}$ cells $/ \mathrm{mL}$ and subcutaneously injected into the right front leg of nude mice. When the size of tumors reached approximately $90 \mathrm{~mm}^{3}$ on day 10 after injection, the mice were randomly divided into 3 groups with 6 mice in each group and used to investigate anti-tumor activity. The mice were injected with the $10 \%$ Tween- 80 , UA/MTX combination, and MTX-UA NPs $(9 \mathrm{mg} / \mathrm{kg}$ of UA, $2.25 \mathrm{mg} / \mathrm{kg}$ of MTX) at two-day intervals. The tumor size and body weight were individually measured once every second day for 10 consecutive days. The tumor volume was macroscopically measured with a caliper, and tumor volume (V) and tumor inhibition rate (\%) were calculated according to the following formula:

The tumor volume $\left(\mathrm{V}, \mathrm{mm}^{3}\right)=$ length (the longest diameter $) \times$ width $^{2}$ (the shortest diameter $) \times 0.5$

Tumor inhibition rate $(\%)=$ (mean tumor weight of control group - mean tumor weight of treated group)/mean tumor weight of control group $\times 100 \%$

Treated mice were sacrificed in day 20 , and tumors were excised to evaluate the tumor inhibition. Organs including heart, liver, spleen, lung, and kidneys were harvested and fixed in 4\% paraformaldehyde solution, then embedded in paraffin, and stained with eosin and hematoxylin.

\section{Statistical Analysis}

Experimental data are presented as the mean \pm standard deviation (SD). Differences between groups were analyzed by $T$-test. Differences were considered significant statistically when p-values were $<0.05$. 


\section{Results and Discussion}

Preparation and Optimization of MTX-UA NPs

Self-assembly plays a significant role in nanobiotechnology involving drug delivery carriers. In this study, UA and MTX, which have poor solubility in water, were nanosized to improve their bioavailability using a selfassembly approach based on the solvent exchange method. $^{22}$ The size of NPs is a significant factor which allows particulates to enter the porous interstitium of solid tumors. Therefore, to obtain suitable UA NPs, their preparation in different solvents, concentrations, and volume ratios (organic phase: aqueous phase) of UA solution were investigated. First, different solvents such as acetone, methylene chloride, ethanol, and methanol were evaluated. Methylene chloride is immiscible with water, and produces large particle sizes $(870.9 \mathrm{~nm})$, which may be influenced by the diffusion properties from solvent phase to water phase. The viscosity of organic phase solvents may also influence the character of NPs. The size achieved was over $200 \mathrm{~nm}$ in ethanol, which may be caused by the significant viscosity of ethanol. However, when UA was dissolved in methanol, a more suitable size $(179.3 \mathrm{~nm})$ and preferable polydispersity index (PDI) of 0.198 of the NPs were obtained (Table 1A). Next, different UA concentrations $(3-7 \mathrm{mM})$ in methanol and different volume ratios from 1:2.5 to $1: 20\left(\mathrm{MeOH}: \mathrm{H}_{2} \mathrm{O}\right)$ were also investigated. The results showed that NPs were smaller in size and had a better PDI in the concentration of $5 \mathrm{mM}$ (Table 1B), and the best NPs volume ratio $\left(\mathrm{MeOH}: \mathrm{H}_{2} \mathrm{O}\right)$ was 1:5 (Table 1C), which was in agreement with previous reports. $^{23}$ However, when MTX alone was dropped into water, the size obtained was large (1131.5 $\mathrm{nm}$ ) and the resulting PDI was 0.992, which indicated that MTX could not be nanosized without the help of carriers (Table 1D). Interestingly, after the UA solution was slowly dropped into the above solution, suitable NPs were formed (size, $150.2 \mathrm{~nm}$ and PDI, 0.164) at the molar ratio of 1:4 (MTX to UA). Furthermore, the surface charge of MTX-UA NPs $(-48.2 \mathrm{mV})$ was higher than that of MTX $(3.1 \mathrm{mV})$ and UA-NPs $(-25.4 \mathrm{mV})$, which may be due to interactions between MTX and UA (Figure 2A and B). In general, due to the electric repulsion, a zeta potential greater than $\pm 30 \mathrm{mV}$, interferes with particle contact and thus stabilizes the dispersion of nanocarriers. ${ }^{24,25}$
Table I Optimization of UA NPs and MTX-UA NPs

\begin{tabular}{|l|c|c|c|c|}
\hline \multicolumn{4}{|l|}{ (A) Solvent Optimization of UA } \\
\hline Solvent & Acetone & $\begin{array}{c}\text { Methylene } \\
\text { Chloride }\end{array}$ & Ethanol & Methanol \\
\hline Size (nm) & 254.2 & 870.9 & 276.4 & 179.3 \\
PDI & 0.340 & 0.797 & 0.370 & 0.198 \\
\hline (B) Concentration Optimization of UA \\
\hline Concentration of UA & $\mathbf{3}$ & $\mathbf{5}$ & $\mathbf{7}$ \\
(mM) & \multicolumn{2}{|c|}{} & \\
\hline Size (nm) & 178.4 & 167.5 & 194.2 \\
PDI & 0.161 & 0.114 & 0.170 \\
\hline
\end{tabular}

(C) Ratio (Methanol/Water) Optimization for Forming UA NPs

\begin{tabular}{|l|c|c|c|c|}
\hline $\begin{array}{l}\text { Methanol/ } \\
\text { Water } \\
\text { Ratio }\end{array}$ & I:20 & I:10 & I:5 & I:2.5 \\
\hline Size (nm) & 175.8 & 151.7 & 143.2 & 163.9 \\
PDI & 0.279 & 0.126 & 0.115 & 0.184 \\
\hline
\end{tabular}

(D) Molar Ratio (UA/MTX) Optimization for Forming MTXUA NPs

\begin{tabular}{|l|c|c|c|c|c|}
\hline $\begin{array}{l}\text { MTX/UA } \\
\text { Ratio }\end{array}$ & I:0 & 0:I & I:2 & I:4 & I:8 \\
\hline Size (nm) & II3I.5 & 142.8 & 537.4 & 152.6 & 158.6 \\
PDI & 0.992 & 0.117 & 0.671 & 0.164 & 0.194 \\
Zeta & 3.1 & -25.4 & 1.6 & -48.2 & -37.9 \\
potential & & & & & \\
$(\mathrm{mV})$ & & & & & \\
\hline
\end{tabular}

\section{Characterization of MTX-UA NPs}

An obvious Tyndall effect achieved by MTX-UA NPs suggested the success of nanoscale particles, while free MTX could not be nanosized in water through the Tyndall effect (Figure 2C). The TEM images of MTX-UA NPs displayed near-spherical morphology with a size of $\sim 150$ $\mathrm{nm}$ (Figure 2D and E), which was consistent with the DLS results. In the UV-vis absorbance spectra, the characteristic absorption peaks of UA (206 nm) and MTX (300 nm) in MTX-UA NPs were lower than that of free MTX, indicating MTX was encapsulated in UA NPs (Figure 2F). The electrostatic interactions in MTX-UA NPs were explored first to confirm the interaction between UA and MTX. When the electrostatic interactions between NPs were destroyed by a high ionic solution $(\mathrm{NaCl})$, the turbidity of the suspension increased and the characteristic UV 


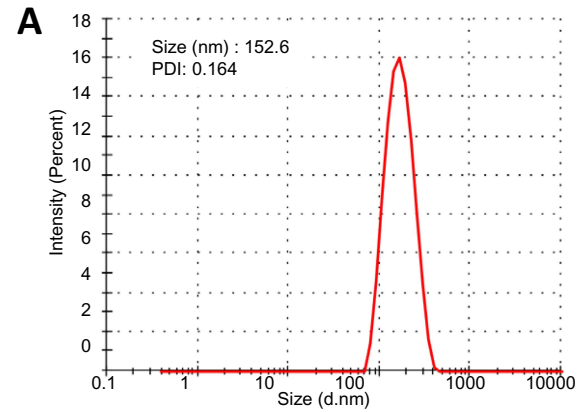

D
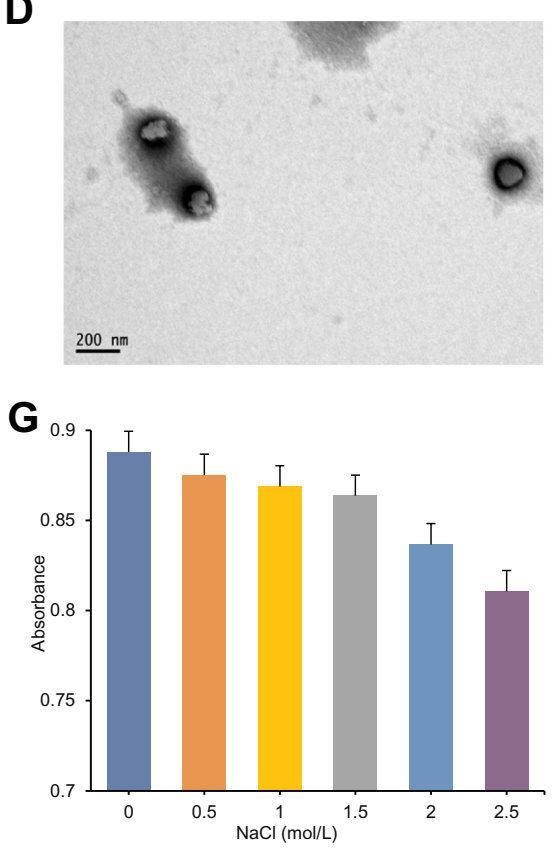
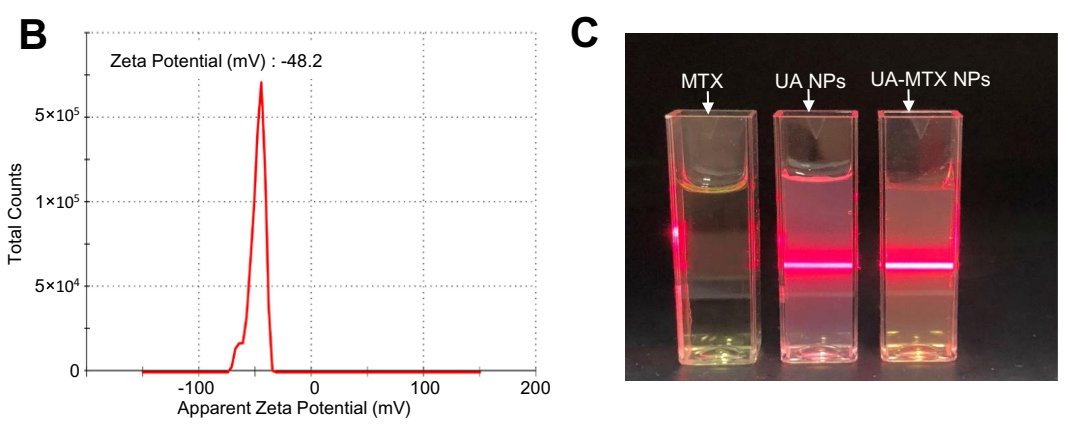

$E$
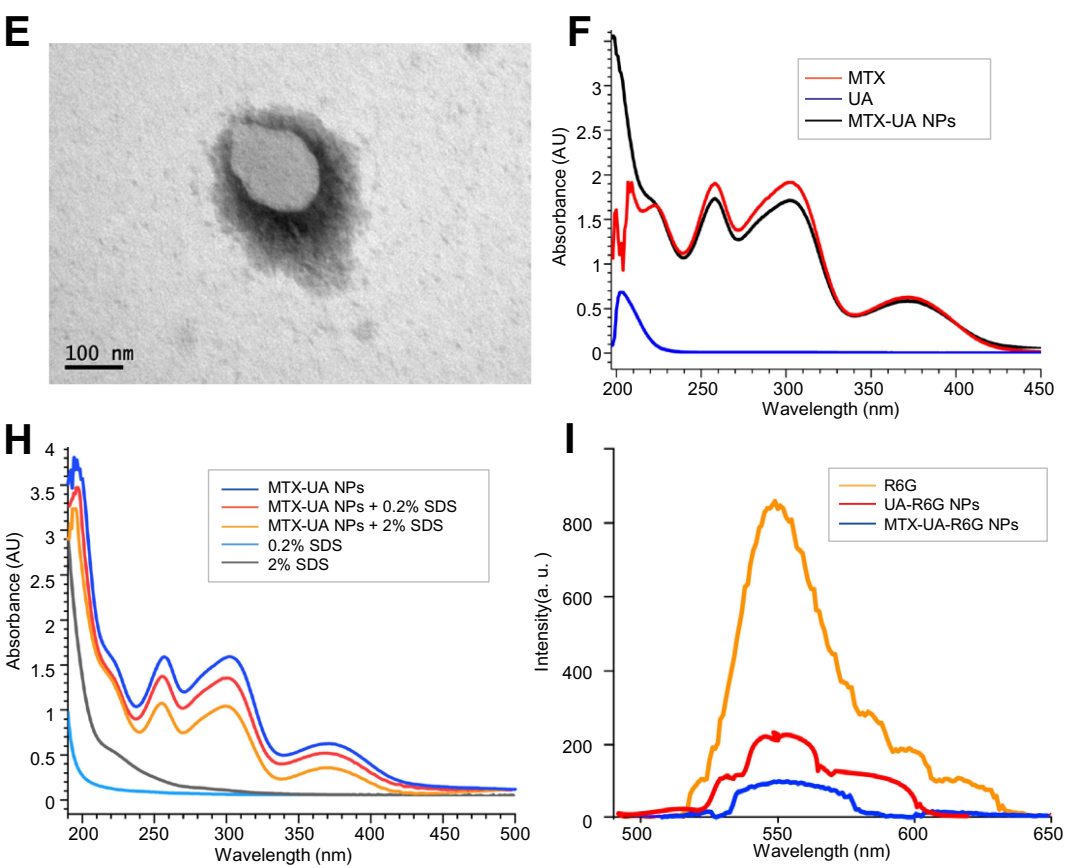

Figure 2 Characterization of the MTX-UA NPs.(A) Diameter. (B) Zeta potential. (C) Tyndall effect. (D) TEM analysis at $200 \mathrm{~nm}$. (E) TEM analysis at I00 nm. (F) UV absorption spectra of MTX, UA and MTX-UA NPs. (G) UV absorption of MTX-UA NPs in NaCl solution. (H) UV absorption spectra of MTX-UA NPs in SDS solution. (I) Fluorescence spectra of free R6G, UA-R6G NPs and MTX-UA-R6G NPs.

absorbance decreased. ${ }^{26}$ As the $\mathrm{NaCl}$ concentration gradually increased, the UV absorbance of MTX-UA NPs decreased, which indicated that MTX-UA NPs were disassembled in a high ionic strength environment and electrostatic interactions occurred during the co-assembly process (Figure 2G). Furthermore, when MTX-UA NPs were diluted by the sodium dodecyl sulfate (SDS, $0.2 \%$ and $2 \% \mathrm{w} / \mathrm{v}$ ), the UV absorption of MTX-UA NPs was also markedly decreased (Figure $2 \mathrm{H}$ ), which might be attributed to the structure changes of MTX-UA NPs due to the hydrophobic interactions of SDS. Based on the above results, it could be inferred that hydrophobic interactions and electrostatic interactions occurred in MTX-UA NPs. To study the uptake of nanoparticles by cells, nanoparticles labeled with rhodamine 6G (UA-R6G NPs and MTX-UA R6G NPs) were prepared and their fluorescence intensity was detected. The resulting fluorescence intensity of the two NPs was lower than that of free R6G at the same concentrations, which suggested that the R6G was successfully encapsulated in nanoparticles (Figure 2I).

\section{Drug Loading Efficiency and Stability of MTX-UA NPs}

The high drug loading capacity of a nanodrug delivery system is vital for its successful application. With the optimized ratio of MTX to UA (1:4, molar ratio), about $96.86 \%$ UA and $91.69 \%$ MTX were incorporated into self-assembled MTX-UA NPs. In addition, the LE (\%) of both components in MTX-UA NPs was determined to be UA $80.79 \%$ and MTX 19.21\%, respectively (Table S1). The high loading capacity was achieved via the carrier-free NPs obtained by the self-assembly approach, simplifying the nano-system. To test the stability of self-assembled NPs, the size (nm) and 
zeta potential $(\mathrm{mV})$ were measured at various timepoints. In water, PBS, and DMEM medium (contained 10\% FBS), there were no marked changes in either size or zeta potential of NPs observed for 7 days (Figure 3A and B). The above results illustrated that self-assembled MTX-UA NPs exhibited a high drug loading and a good stability.

\section{In vitro Drug Release of UA and MTX from MTX-UA NPs}

It has been reported that the microenvironment of the tumor is slightly acidic. ${ }^{27}$ To investigate $\mathrm{pH}$-responsive release of MTX-UA NPs, the release drug assay was conducted under $\mathrm{pH} 5.0$ to imitate the acidic conditions of the tumor and under $\mathrm{pH} 7.4$ to imitate the physiological conditions. Compared to physiological conditions $(\mathrm{pH}=7.4)$, the size of the MTX-UA NPs increased dramatically and there was visible turbidity under acidic conditions $(\mathrm{pH}=5.0)$, which suggested that electrostatic interactions were potentially broken by protonation (Figure 3C and F). Moreover, the drug release rate was detected by HPLC (Figure S1). As shown in Figure 3E, over $80 \%$ of free MTX was rapidly released over $4 \mathrm{~h}$ at $37^{\circ} \mathrm{C}$. Compared to free MTX, MTX from MTX-UA NPs showed a sustained release. Moreover, the release of MTX from MTX-UA NPs was pH-dependent as about $50 \%$ of MTX was released from MTX-UA NPs at pH 5.0 over 24 h, while about $20 \%$ of MTX was released from MTX-UA NPs at $\mathrm{pH} 7.4$, indicating that the drug could be released from MTX-UA NPs in the acidic conditions of the tumor. A similar drug release of UA from MTX-UA NPs is shown in Figure 3D, suggesting that UA and MTX could be released synchronously from MTX-UA NPs. Given the above findings, self-assembled MTX-UA NPs might retain an intact formulation throughout the blood circulation, and once reaching the tumor site, MTX-UA NPs would release drugs in an acidic environment of the tumors. Moreover, we conducted in vivo pharmacokinetic studies using Wistar rats, which were assessed by UPLC-MS/MS (Figure S2).

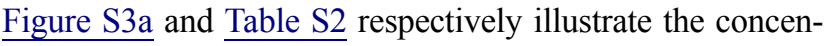
tration- and time-dependent curves of MTX and UA in the plasma and the pharmacokinetic parameters of MTX and
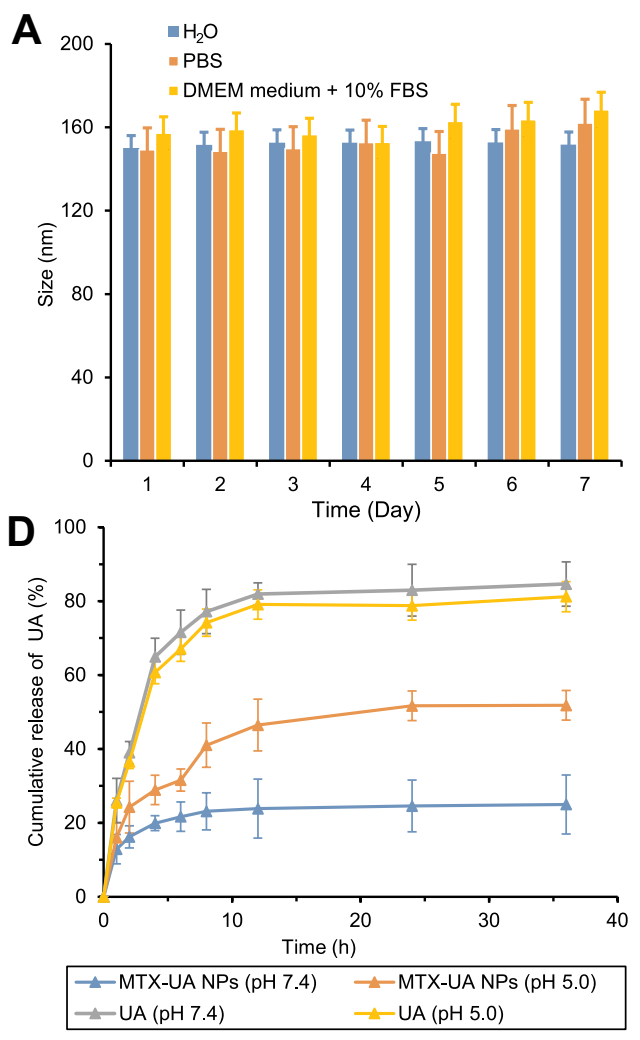
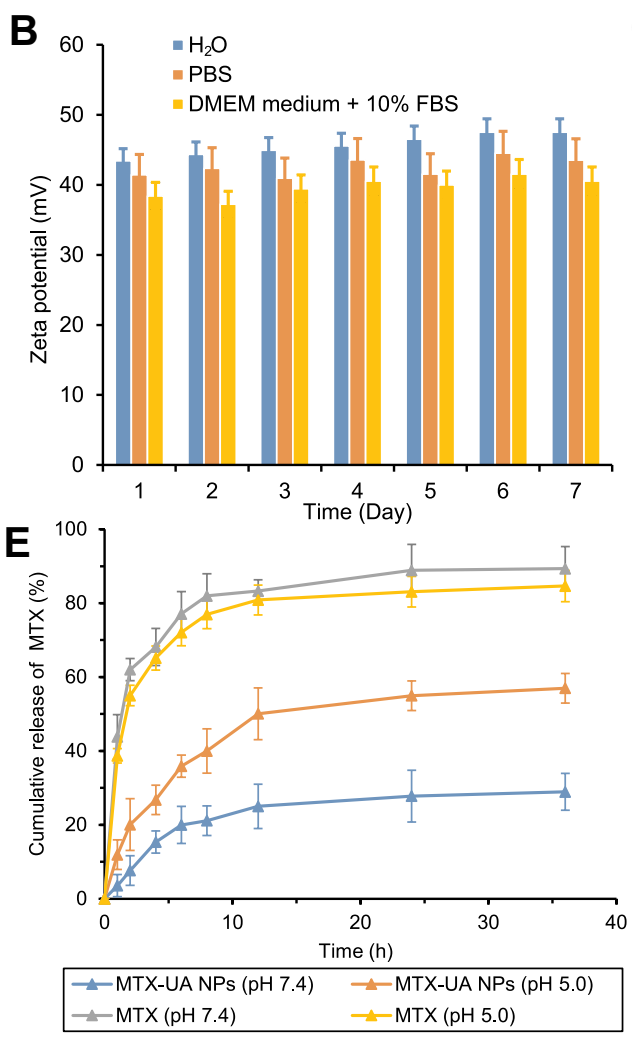

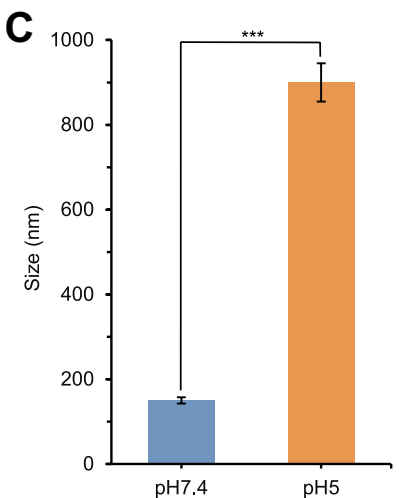

$\mathbf{F}$

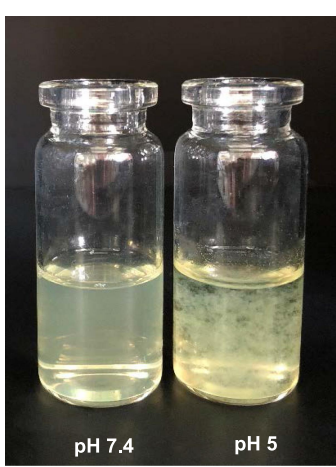

Figure 3 Stability and drug release of MTX-UA NPs. (A) Size of MTX-UA NPs in $\mathrm{H}_{2} \mathrm{O}$, PBS solution and DMEM medium containing $10 \%$ FBS for 7 days. (B) Zeta potential of MTX-UA NPs in $\mathrm{H}_{2} \mathrm{O}$, PBS solution and DMEM medium containing 10\% FBS for 7 days. (C) Size of MTX-UA NPs in the solution at various pH values. (D) Cumulative drug release profiles of UA from MTX-UA NPs under different $\mathrm{pH}$ conditions. (E) Cumulative drug release profiles of MTX from MTX-UA NPs under different $\mathrm{pH}$ conditions. (F) Photo of $\mathrm{pH}$ response. $* * * \mathrm{p} p 0.00 \mathrm{I}$. 
UA following intravenous injection of MTX-UA NPs (at a dosage of $5 \mathrm{mg} / \mathrm{kg}$ for MTX and $20 \mathrm{mg} / \mathrm{kg}$ for UA). The elimination half-life $\left(\mathrm{t}_{1 / 2} \mathrm{z}\right)$ for MTX and UA was 15.60 $\pm 4.23 \mathrm{~h}$ and $9.89 \pm 7.76 \mathrm{~h}$, respectively, while the mean residence time $\left(\mathrm{MRT}_{0-\mathrm{t}}\right)$ was $1.75 \pm 0.40 \mathrm{~h}$ and $5.41 \pm 3.29$ h. Thus, MTX and UA could be absorbed and rapidly metabolized. The peak blood concentration $\left(\mathrm{C}_{\max }\right)$ of MTX and UA in plasma was $19.44 \pm 6.33$ and 8.94 $\pm 2.69 \mathrm{mg} / \mathrm{L}$, while the area under the curve (AUC) of MTX and UA was $11.35 \pm 4.40$ and $4.81 \pm 0.33 \mathrm{mg} / \mathrm{L}^{*} \mathrm{~h}$. These pharmacokinetic properties indicated that MTX-UA NPs offered a high concentration of circulating MTX and UA in the body, which ensured MTX and UA could be delivered to the tumor site. Moreover, the drug concentration at tumor sites of nude mice as indicated in the In vivo anti-tumor effects of MTX-UA NPs section below was also determined by UPLC-MS/MS. Figure S3b shows that the concentration of MTX and UA in tumors of MTX-UA NPstreated groups was higher than that of the carrier-free UA/ MTX mixture groups, which also indicated that MTX-UA NPs could deliver more drugs to the tumor site, to exhibit a better anticancer effect.

\section{Cellular Uptake Assays}

Numerous studies have reported that the folate receptor was overexpressed in most cancer cells. The molecular structure of MTX is similar to that of folic acid (FA) and both are ligands of folate receptors. The MTX modified nanodrugs are quickly recognized by folate receptors and increase the endocytosis rate, thus enhancing its therapeutic effect. ${ }^{28}$ As shown in Figure S4, when cells were treated with UA, MTX and $\mathrm{R} 6 \mathrm{G}$ as separate treatments, only the cells exposed to R6G produced a yellow fluorescence under excitation of 488 nm. Hence, the MTX-UA NPs and UA NPs were labeled with R6G to study the targeting of folate-receptors. As shown in Table S3, the size (148.6 nm) and PDI (0.174) of UA-R6G NPs and size (147.9 nm) and PDI (0.169) MTXUA-R6G NPs were not significantly different from those of with UA NPs and MTX-UA NPs. Moreover, MCF-7 cells (folate receptor over-expressing cells) and A549 cells (folate receptor low-expressing cells) were selected to provide further evidence on targeting of the folate-receptors. ${ }^{29}$

As shown in Figure 4, the increase in R6G fluorescence intensity was time-dependent. In A549 cells, the intensity of R6G fluorescence increased slowly, with no difference in the

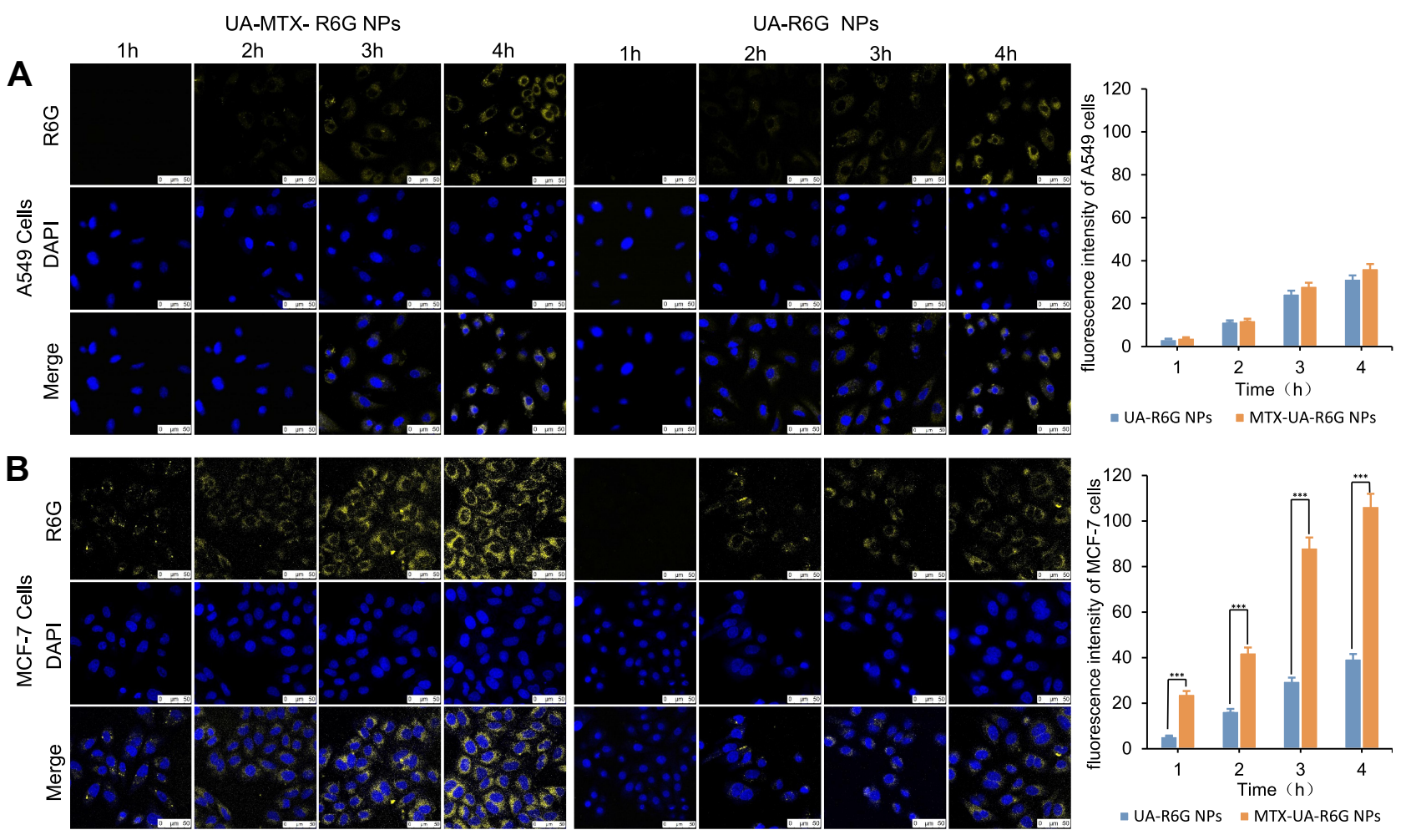

Figure 4 In vitro experiments of cells uptake. (A) CLSM images of MCF-7 cells incubated with MTX-UA-R6G NPs and UA-R6G NPs following I h, 2 h, 3 h and 4 h. (B) CLSM images of A549 cells incubated with MTX-UA-R6G NPs and UA-R6G NPs following I h, $2 \mathrm{~h}, 3 \mathrm{~h}$ and $4 \mathrm{~h}$. *** $p<0.001$. 
endocytosis rate between UA-R6G NPs and MTX-UA-R6G NPs (Figure 4A), due to the limited targeting and lowexpression of folate receptors in A549 cells. Conversely, in MCF-7 cells endogenously over-expressing folate receptors, the fluorescence intensity of MTX-UA-R6G NPs was significantly higher than that of UA-R6G NPs (Figure 4B), indicating the specific binding of MTX-UA-R6G NPs in MCF-7 cells because of the high-expression of folate receptors in MCF-7 cells. These results confirmed the ability of MTX-UA NPs to target MCF-7 cells.

\section{In vitro Cytotoxicity and Synergistic Profiles of MTX-UA NPs}

To quantify the synergistic effects between UA and MTX, a standard CCK-8 proliferation assay was performed to calculate the combination index of the NPs preparation
(CI, inducing 50\% inhibition of cell viability). CI was measured at various molar ratios of MTX to UA (from $1: 1$ to $1: 8)$. As shown in Figure $5 \mathrm{D}$ and $\mathrm{E}$, the synergistic effects were indicated as $\mathrm{CI}<1$ and lower $\mathrm{IC}_{50}$ values were observed with drug combinations. At the molar ratio of $1: 4$, the CI value was lowest and the two drugs exerted the strongest synergistic effect. The $\mathrm{IC}_{50}$ of MTX and UA decreased to $29.9 \mu \mathrm{M}$ and $7.48 \mu \mathrm{M}$, respectively, compared to the effects induced by the free drug. More importantly, the molar ratio of MTX to UA in the NPs preparations was also 1:4, which also achieved the maximum synergistic effect.

To determine the potential for biomedical applications, the cytotoxicity of NPs was studied in cancer cells exhibiting different folate receptor expression. Thus, A549 cells and MCF-7 cells were, respectively, incubated with various
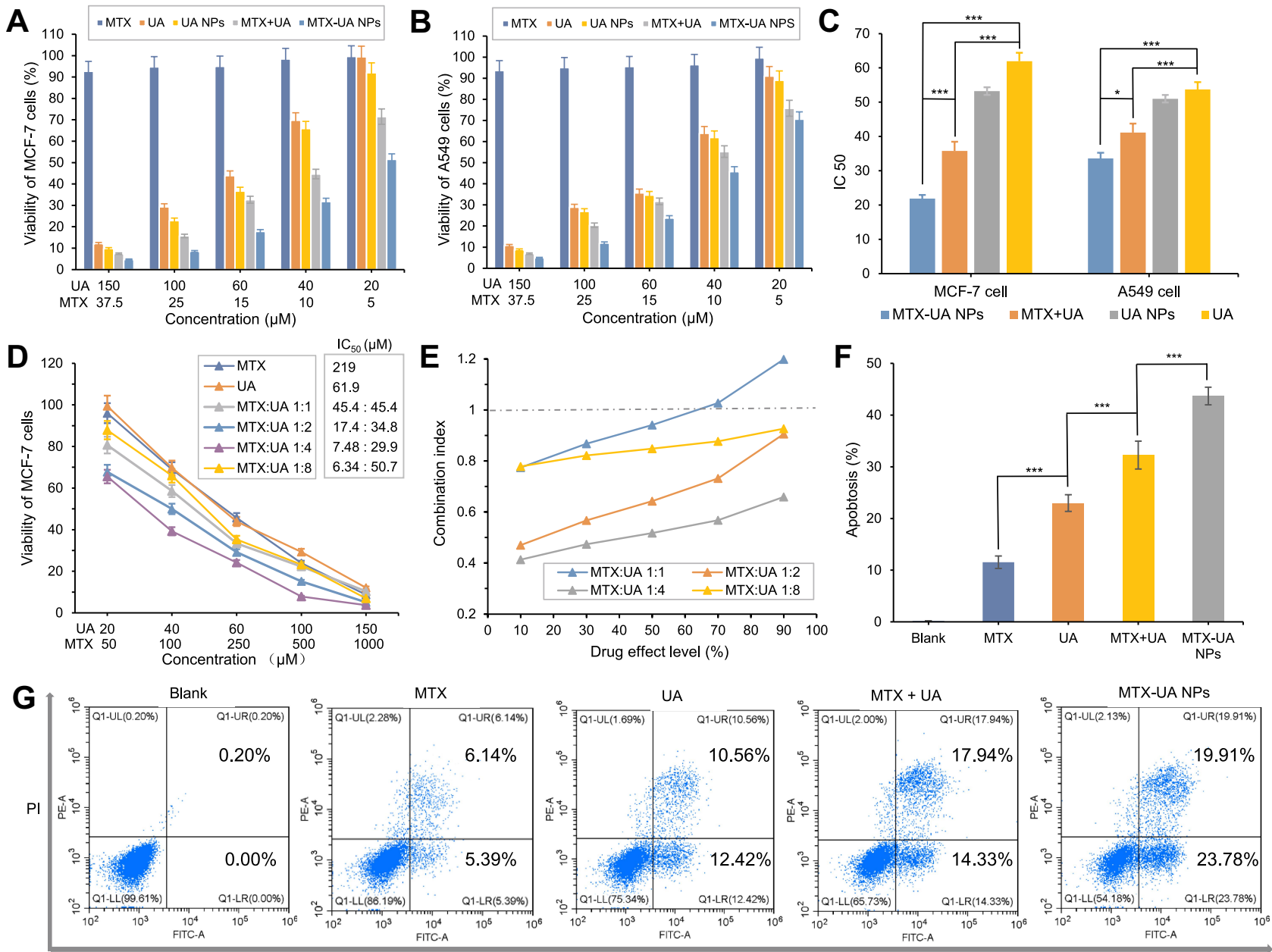

Figure 5 The synergistic effect of UA and MTX, and the cytotoxicity in vitro. The cell viability of (A) A549 cells and (B) MCF-7 cellls cultivated with UA, UA NPs, MTX/UA, MTX-UA NPs for $24 \mathrm{~h}$ in vitro. (C) IC 50 value of UA, UA NPs, MTX/UA, MTX-UA NPs to MCF-7 cells and A549 cells (calculated by concentration of UA). (D) Cell viability (\%) of UA, MTX and various fixed molar ratios of two drugs. (E) Combination index of the synergistic effects at various fixed molar ratio of UA and MTX. (F) and (G) Apoptosis rate of UA, UA NPs, MTX/UA and MTX-UA NPs against MCF-7 cell. $* p<0.05, * * p<0.001$. 
concentrations of free UA, free MTX, MTX/UA, and MTXUA NPs for $24 \mathrm{~h}$. As shown in Figure $5 \mathrm{~A}$ and $\mathrm{B}$, the inhibitory activity of MTX-UA NPs was significantly increased compared with the free UA, MTX, and MTX/UA groups. The $\mathrm{IC}_{50}$ of MTX-UA NPs was also compared with that of free UA, UA NPs, MTX/UA groups in MCF-7 cells and A549 cells (the $\mathrm{IC}_{50}$ calculated according to the concentration of UA). As shown in Figure 5C, compared to free UA, the $\mathrm{IC}_{50}$ of MTXUA NPs was significantly decreased by $64.70 \%$ in MCF-7 cells, whereas in the MTX/UA group, the $\mathrm{IC}_{50}$ decreased by only $42.24 \%$. Moreover, the cytotoxicity of MTX-UA NPs against MCF-7 cells was 1.54-fold than that against A549 cells. These results showed that the cytotoxicity of MTX-UA NPs improved by the targeting of folate receptors and the synergistic effects of the MTX and UA combination.

The Annexin V-FITC/PI assay was conducted to investigate the biological effects of MTX-UA NPs on cell apoptosis. MCF-7 cells treated with MTX-UA NPs had a higher apoptosis rate of $43.69 \%$ than free MTX (11.53\%), UA (22.98\%), or MTX/UA (32.72\%) (Figure $5 \mathrm{~F}$ and $\mathrm{G})$, which was consistent with the cytotoxicity results and suggests that these effects might contribute to the efficacy of the combination therapy and to the folatereceptor targeting of MTX-UA NPs.

\section{In vivo Anti-Tumor Effects of MTX-UA NPs}

Given the significant inhibitory effects of MTX-UA NPs on MCF-7 cells observed in vitro, the anti-tumor abilities of MTX-UA NPs were investigated in vivo using a MCF7-xenografted tumor model. Nude mice were injected intravenously with MTX-UA NPs and UA/MTX combination solutions (dissolved in 10\% Tween 80 ) at the same concentration; $10 \%$ Tween 80 was used as the control treatment group. Body weight and tumor volumes of mice were measured every 2 days. As shown in Figure 6A, there was no effect on the body weight of nude mice when treated with drugs, supporting its safety in tumor-bearing mice. Moreover, the tumor volumes in the UA-MTX NPs group were smaller than that in the UA/MTX combination treatment group (Figure 6B). After 10 days, mice were euthanized, and tumors were excised and weighed. The tumor volumes and weights of control and UA/MTX combination treatment groups were significantly higher than that of the MTX-UA NPs group (Figure 6C and D). Moreover, the drug concentration in tumors was also evaluated by UPLC-MS /MS. In Figure S3b, the results showed that the concentration of MTX and UA in tumors of MTX-UA NPs groups was higher than that of the UA/MTX combination groups.
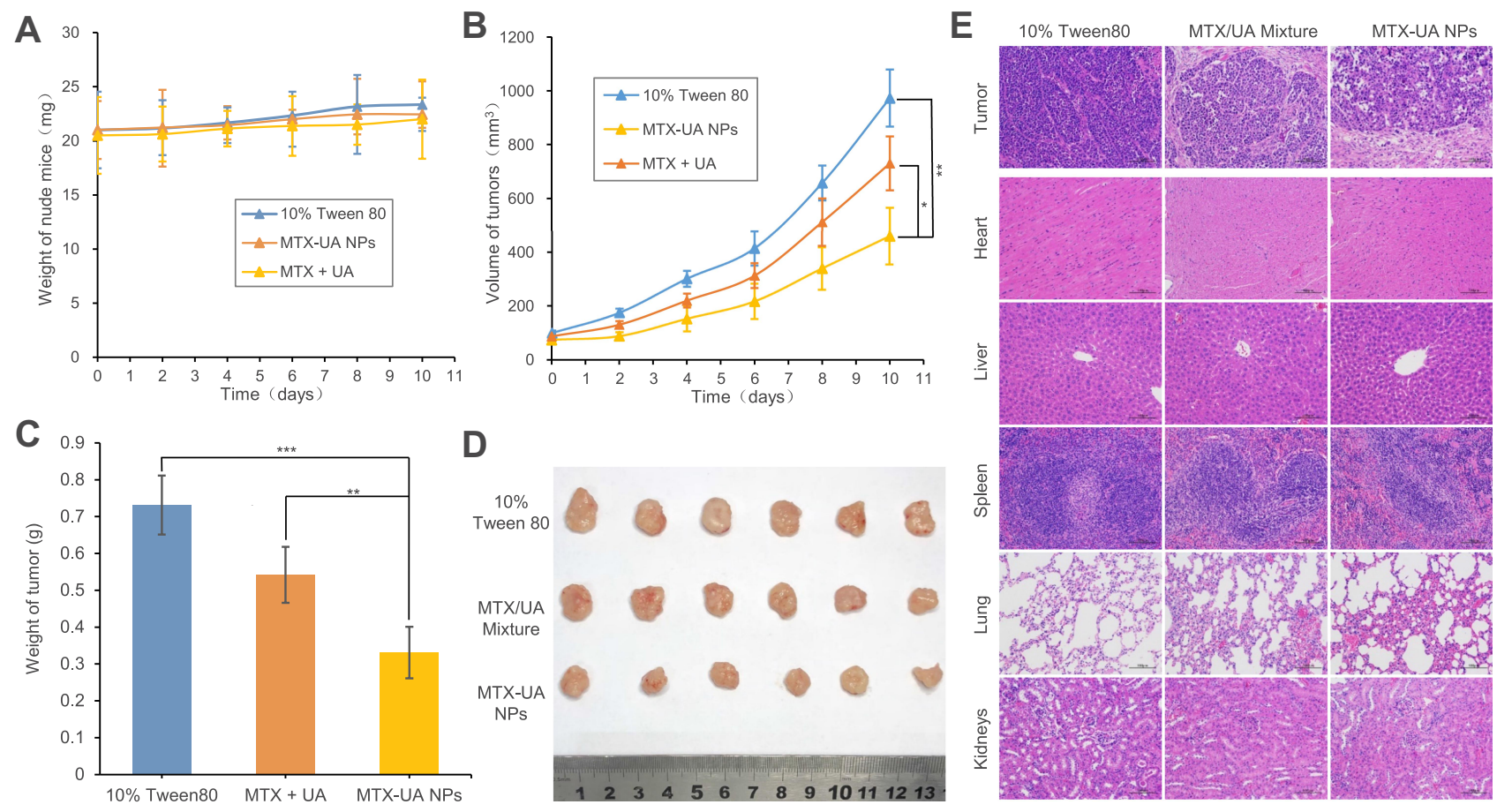

Figure 6 In vivo anti-tumor effects of MTX-UA NPs on nude mice bearing MCF-7 tumors. (A) Body weight changes of mice. (B) Tumor growth curve. (C) Mean weight of tumors. (D) Images of the excised MCF-7 tumor tissues at 20 days post-implantation. (E) Representative histology of MCF-7 tumor tissue and other organs after the administration of $10 \%$ Tween 80 , UA/MTX mixture and MTX/UA NPs. Nuclei were stained blue, whereas the extracellular matrix and cytoplasm were stained red in the H\&E analysis. The scale bar is $100 \mu \mathrm{m} . * p<0.05, * * p<0.01, * * * p<0.001$. 
The tumor inhibition rates (\%) of the UA/MTX combination and MTX-UA NPs were $20.54 \%$ and $49.31 \%$, respectively, which is indicative of a synergetic anticancer effect.

Histological analysis was further performed to evaluate the biological safety of MTX-UA NPs. None of the organs in either group (kidney, liver, spleen, heart, and lung) revealed any pathological changes, indicating that MTX-UA NPs induced no significant toxicity. In addition, tumor cells in the control group had the highest density, regular morphology, and normal nuclei, while tumor cells in the MTX-UA NPs exhibited irregular morphology and significantly reduced nuclei (Figure 6E). Based on the above findings, MTX-UA NPs have potential application in cancer treatment.

\section{Conclusion}

In this study, a carrier-free formulation combining UA and MTX, to produce a self-assembled tumor-targeted drug delivery system was designed. The MTX-UA NPs were prepared and characterized, and presented a NP size of approximately $150 \mathrm{~nm}$ with a high drug EE and LE. In addition, MTX-UA NPs exhibited good stability and rapid release of UA or MTX in an acidic environment. The pharmacokinetic results showed that MTX-UA NPs could prolong the circulation of both MTX and UA in the blood, which allowed sufficient time to accumulate at the tumor site. Furthermore, MTX-UA NPs could enhance the cellular uptake of UA and MTX in folate receptor-positive cancer cells. Further, the cytotoxicity testing demonstrated that UA could sensitize MTX to improve its anticancer effects and displayed stronger anti-proliferative effects on MCF-7 cells. In addition, our in vivo findings suggested that combination therapy with the MTX-UA NPs could significantly enhance the anti-tumor efficacy of MTX and UA, while presenting a suitable biological safety profile. In summary, these results suggested that MTX-UA NPs could enhance anti-cancer effects via a targeted cancer therapy.

\section{Abbreviations}

MTX-UA-NPs, methotrexate-ursolic acid nanoparticles; PDI, polydispersity index; DHFR, dihydrofolate reductase; THF, tetrahydrofolate; FA, folate; DMSO, dimethyl sulphoxide; ATCC, American Type Culture Collection; FITC, fluorescein isothiocyanate; FBS, fetal bovine serum; DMEM, dulbecco's modified eagle's medium; TEM, transmission electron microscope; SDS, sodium dodecyl sulfate; EE, encapsulation efficiency; LE, loading efficiency; HPLC, high-performance liquid chromatography; CI, combination index.

\section{Acknowledgments}

This work was supported by a program of the National Natural Science Foundation of China [grant numbers 81872981]; the Key Projects of Shanghai 3-Year Plan [grant number ZY (2018-2020)-CCCX-2001-04]; the National Scientific and Technological Major Special Project of China [grant number 2019ZX09201004-002]; the Shanghai Science and Technology innovation project [grant number 17401901900]; projects sponsored by the development fund for Shanghai Talents [grant number 2018105]; the Youth Talent Sail Plan from the Shanghai Committee of Science and Technology [grant number 18YF1423600]; the Program of Shanghai Academic/Technology Research Leader [grant number 18XD1403700]; and a Project of the Shanghai Committee of Science and Technology [grant number 20S21902500].

\section{Disclosure}

The authors report no conflicts of interest in this work.

\section{References}

1. Jemal A, Center MM, DeSantis C, et al. Ward, global patterns of cancer incidence and mortality rates and trends. Cancer Epidemiol Biomarkers Prev. 2010;19(8):1893-1907. doi:10.1158/1055-9965. EPI-10-0437

2. Kumari P, Ghosh B, Biswas S. Nanocarriers for cancer-targeted drug delivery. J Drug Target. 2016;24(3):179-191. doi:10.3109/ 1061186X.2015.1051049

3. Kozminski P, Halik PK, Chesori R, et al. Overview of dual-acting drug methotrexate in different neurological diseases, autoimmune pathologies and cancers. Int J Mol Sci. 2020;21:3438-3476.

4. Abolmaali SS, Tamaddon AM, Dinarvand R. A review of therapeutic challenges and achievements of methotrexate delivery systems for treatment of cancer and rheumatoid arthritis. Cancer Chemother Pharmacol. 2013;71(5):1115-1130. doi:10.1007/s00280-012-2062-0

5. Wood GS, Wu J. Methotrexate and pralatrexate. Dermatol Clin. 2015;33(4):747-755. doi:10.1016/j.det.2015.05.009

6. Zhang H, Li Y, Pan Z, et al. Multifunctional nanosystem based on graphene oxide for synergistic multistage tumor-targeting and combined chemo-photothermal therapy. Mol Pharm. 2019;16:1982-1998. doi:10.1021/acs.molpharmaceut.8b01335

7. Ji X, Guo H, Tang Q, Ma D, Xue W. A targeted nanocarrier based on polyspermine for the effective delivery of methotrexate in nasopharyngeal carcinoma. Mater Sci Eng C Mater Biol Appl. 2017;81:48-56. doi:10.1016/j.msec.2017.07.036

8. Zhu S, Wang Q, Jiang J, et al. A conjugate of methotrexate and an analog of luteinizing hormone releasing hormone shows increased efficacy against prostate cancer. Sci Rep. 2016;6(1):33894-33903. doi:10.1038/srep33894

9. Howar SC, McCormick J, Pui CH, et al. Preventing and managing toxicities of high-dose methotrexate. Oncologist. 2016;21 (12):1471-1482. doi:10.1634/theoncologist.2015-0164

10. Ren J, Fang Z, Yao L, et al. A micelle-like structure of poloxamer-methotrexate conjugates as nanocarrier for methotrexate delivery. Int $J$ Pharm. 2015;487(1-2):177-186. doi:10.1016/j. ijpharm.2015.04.014

11. Feng X, Chen A, Zhang Y, et al. Application of dental nanomaterials: potential toxicity to the central nervous system. Int $J$ Nanomed. 2015;10:3547-3565. doi:10.2147/IJN.S79892 
12. Fumagalli G, Marucci C, Christodoulou MS, et al. Passarella, self-assembly drug conjugates for anticancer treatment. Drug Discov Today. 2016;21(8):1321-1329. doi:10.1016/j. drudis.2016.06.018

13. Yadav S, Sharma AK, Kumar P. Nanoscale self-assembly for therapeutic delivery. Front Bioeng Biotechnol. 2020;8:127-151. doi:10.3389/fbioe. 2020.00127

14. Wang J, Zhao H, Zhi K, et al. Exploration of the natural active small-molecule drug-loading process and highly efficient synergistic antitumor efficacy. ACS Appl Mater Interfaces. 2020;12 (6):6827-6839. doi:10.1021/acsami.9b18443

15. Ariga K, Nishikawa M, Mori T, et al. Self-assembly as a key player for materials nanoarchitectonics. Sci Technol Adv Mater. 2019;20 (1):51-95. doi:10.1080/14686996.2018.1553108

16. Lu J, Hu J, Liang Y, et al. The supramolecular organogel formed by self-assembly of ursolic acid appended with aromatic rings. Materials. 2019;12(4):614-623. doi:10.3390/ma12040614

17. Dar BA, Lone AM, Shah WA, et al. Synthesis and screening of ursolic acid-benzylidine derivatives as potential anti-cancer agents. Eur J Med Chem. 2016;111:26-32. doi:10.1016/j.ejmech.2016.01.026

18. Zhang X, Song X, Yin S, et al. p21 induction plays a dual role in anti-cancer activity of ursolic acid. Exp Biol Med. 2016;241 (5):501-508. doi:10.1177/1535370215616195

19. Bacanli M, Basaran AA, Basaran N. The antioxidant, cytotoxic, and antigenotoxic effects of galangin, puerarin, and ursolic acid in mammalian cells. Drug Chem Toxicol. 2017;40(3):256-262. doi:10.1080/ 01480545.2016.1209680

20. Li C, Lin J, Wu P, et al. Small molecule nanodrug assembled of dual-anticancer drug conjugate for synergetic cancer metastasis therapy. Bioconjug Chem. 2018;29:3495-3502. doi:10.1021/acs. bioconjchem. $8 \mathrm{~b} 00657$

21. Guo Y, Jiang K, Shen Z, et al. A small molecule nanodrug by self-assembly of dual anticancer drugs and photosensitizer for synergistic near-Infrared cancer theranostics. ACS Appl Mater Interfaces. 2017;9(50):43508-43519. doi:10.1021/acsami.7b14755
22. Oliyaei N, Moosavi-Nasab M, Tamaddon AM, et al. Preparation and characterization of porous starch reinforced with halloysite nanotube by solvent exchange method. Int $J$ Biol Macromol. 2019;123:682-690. doi:10.1016/j.ijbiomac.2018.11.095

23. Jiang K, Han L, Guo Y, et al. A carrier-free dual-drug nanodelivery system functionalized with aptamer specific targeting HER2-overexpressing cancer cells. J Mater Chem B. 2017;5 (46):9121-9129. doi:10.1039/C7TB02562A

24. Jain AK, Thareja S. In vitro and in vivo characterization of pharmaceutical nanocarriers used for drug delivery. Artif Cells Nanomed Biotechnol. 2019;47:524-539. doi:10.1080/21691401.2018.1561457

25. Fornaguera C, Solans C. Characterization of polymeric nanoparticle dispersions for biomedical applications: size, surface charge and stability. Pharm Nanotechnol. 2018;6(3):147-164. doi:10.2174/ 2211738506666180706121515

26. Liu Y, Qiao L, Xiang Y, et al. Adsorption behavior of low-concentration imidazolium-based ionic liquid surfactant on silica nanoparticles. Langmuir. 2016;32(11):2582-2590. doi:10.1021/acs. langmuir.6b00302

27. Peppicelli S, Andreucci E, Ruzzolini J, et al. The acidic microenvironment as a possible niche of dormant tumor cells. Cell Mol Life Sci. 2017;74(15):2761-2771. doi:10.1007/s00018-017-2496-y

28. Nogueira E, Sarria MP, Azoia NG, et al. Internalization of methotrexate conjugates by folate receptor-alpha. Biochemistry. 2018;57:6780-6786. doi:10.1021/acs.biochem.8b00607

29. Soe ZC, Thapa RK, Ou W, et al. Folate receptor-mediated celastrol and irinotecan combination delivery using liposomes for effective chemotherapy. Colloids Surf B Biointerfaces. 2018;170:718-728. doi:10.1016/j.colsurfb.2018.07.013
International Journal of Nanomedicine

\section{Publish your work in this journal}

The International Journal of Nanomedicine is an international, peerreviewed journal focusing on the application of nanotechnology in diagnostics, therapeutics, and drug delivery systems throughout the biomedical field. This journal is indexed on PubMed Central, MedLine, CAS, SciSearch ${ }^{\circledR}$, Current Contents ${ }^{\circledR} /$ Clinical Medicine,

\section{Dovepress}

Journal Citation Reports/Science Edition, EMBase, Scopus and the Elsevier Bibliographic databases. The manuscript management system is completely online and includes a very quick and fair peer-review system, which is all easy to use. Visit http://www.dovepress.com/ testimonials.php to read real quotes from published authors. 